Aletria, Belo Horizonte, v. 30, n. 1, p. 135-154, 2020

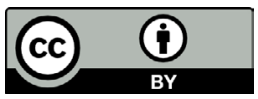

\title{
$O$ pós-colonial como ponto de vista, uma nota sobre Silviano Santiago
}

\section{Towards a Postcolonial Point of View, Notes on Silviano Santiago}

\author{
Mariana Miggiolaro Chaguri \\ Universidade Estadual de Campinas (Unicamp), Campinas, São Paulo / Brasil \\ chaguri@unicamp.br \\ https://orcid.org/0000-0002-5201-360X \\ Maria Caroline Marmerolli Tresoldi \\ Universidade Estadual de Campinas (Unicamp), Campinas, São Paulo / Brasil \\ carolinetresoldi@gmail.com \\ http://orcid.org/0000-0001-8218-5181
}

Resumo: Este artigo argumenta sobre a novidade teórico-metodológica de Uma literatura nos trópicos, de 1978, primeira coletânea de ensaios de Silviano Santiago, observando que se trata da emergência de um ponto de vista pós-colonial para investigar a literatura. Para tanto, sustenta que a diferença como valor crítico e heurístico é afirmada por Santiago por meio do caráter relacional e violento da colonização. Para desdobrar essa hipótese de leitura, o texto promove uma análise que situa o debate sobre a diferença no interior da discussão sobre a dependência para, em seguida, discutir o estatuto teórico-metodológico do conceito de "entre-lugar", destacando os principais aspectos do método crítico proposto pelo autor, bem como explorando algumas de suas consequências.

Palavras-chave: Silviano Santiago; Uma literatura nos trópicos; entre-lugar; pensamento social; estudos pós-coloniais.

Abstract: This paper examines the book The Space In-between: Essays on Latin American Culture, by Silviano Santiago, arguing about the emergence of a post-colonial point of view in its essays. Our hypothesis is that the relational and violent character of 
colonization is the main point of the author's argument about the critics and heuristic's value of difference. The approach described here is structured in three parts: the first and the second ones discuss the concept of "the space in-between", facing arguments related to literary historiography, and the Theory of Dependence, for example. In the third and last part, we explore the theoretical consequences of the concept, suggesting a lecture from the postcolonial point of view.

Keywords: Silviano Santiago; The Space In-between: Essays on Latin American Culture; space in-between; social thought; postcolonial studies.

\section{Uma novidade teórica: breve introdução}

Uma literatura nos trópicos, coletânea de ensaios publicada pela primeira vez em 1978, apresenta gestos que acompanham a produção ensaística de Silviano Santiago. Entre os mais sugestivos, está o esforço crítico de investigar a literatura brasileira e latino-americana a partir de um ponto de vista que, em nosso argumento, seria marcado por uma novidade no debate de seu tempo: a desestabilização da noção de dependência em favor daquilo que chamamos de um ponto de vista pós-colonial, expresso tanto na abordagem proposta para ler os textos literários, quanto na eleição dos textos tomados como objeto de análise.

No primeiro caso, a presença marcante de uma abordagem teórica assentada na intertextualidade e em conceitos e problemas fabulados, sobretudo, por autores franceses como Michel Foucault (Arqueologia do saber, 1969), Jacques Derrida (A escritura e a diferença, 1967) e Gilles Deleuze (Lógica do sentido, 1969), marca os ensaios reunidos em Uma literatura nos trópicos, e destoa de uma vertente mais sociológica de análise crítica e de investigação historiográfica da literatura e da vida cultural brasileira, que foi uma das principais linhas de pesquisa na área de estudos literários entre os anos de 1960 e $1980 .{ }^{1}$

\footnotetext{
${ }^{1}$ Perseguindo as mediações entre literatura e sociedade, essa vertente mais sociológica de investigação da vida social e literária do país possui sua proposição teórico-metodológica sintetizada por Antonio Candido em obras como Formação da literatura brasileira (1959) e Literatura e sociedade (1965), encontrando diferentes desdobramentos ao longo das décadas posteriores, em trabalhos e reflexões de autores como, por exemplo, Roberto Schwarz. No caso de Silviano Santiago, vale reforçar que se trata de um dos principais intelectuais a introduzir o pensamento pós-estruturalista no Brasil, com destaque para a publicação do ensaio "Desconstrução e descentramento" (1973) na revista Tempo
} 
Em “Análise e interpretação", por exemplo, Santiago (2000) é didático na explicação de que sua compreensão do fenômeno literário deriva de uma interpretação centrada na diferença e no diálogo entre textos, o que possibilita pensar a instância de articulação de um texto sobre outros. Aproximando-se de suas palavras, no método crítico baseado na intertextualidade, os textos deixam de ser considerados separadamente ou como participantes de um único modelo, e são interpretados como se "diferenciando na repetição", ou seja, como "um diálogo entre o mesmo e o outro" (SANTIAGO, 2000, p. 208). Essa estratégia de leitura investe no desafio de pensar o diálogo não apenas entre textos, como também entre diferentes culturas geográficas, recolocando a problemática do autor na interpretação literária e mobilizando a diferença como conceito operacional.

Já no que se refere à seleção de obras, Santiago (2000) percorre um longo arco temporal que se inicia no período colonial brasileiro, momento central para perquirir traços do eurocentrismo e das relações hierárquicas que demarcavam a sociedade colonial, e vai até as matérias literárias e as manifestações artísticas que lhe eram contemporâneas, mais precisamente a produção cultural que ele identifica como formadora de uma "nova sensibilidade" sobre o país, inscrita no contexto da censura e do autoritarismo impostos pelo regime civil-militar brasileiro (19641985). ${ }^{2}$ Chama atenção, então, a variedade de textos tomados como objeto

Brasileiro, e do Glossário de Derrida (1976). Tanto esses trabalhos de caráter mais didático quanto parte dos ensaios do autor elaborados em meados da década de 1970 foram gestados em seminários do curso de pós-graduação em Letras, na PUC-Rio, logo após o crítico mineiro voltar ao Brasil de uma temporada no exterior. Sobre o contexto desses seminários, Eneida Cunha (2019) recorda que ainda predominava no círculo carioca próximo ao professor um certo "pensamento francês", dominado pela análise textual e pelos conceitos estruturalistas. Não por acaso, Santiago investiu na produção de trabalhos que contribuíssem para apresentar um "novo pensamento francês", por assim dizer.

${ }^{2}$ Para sublinhar esse ponto, vale mencionar que na versão ampliada do livro lançada em 2019, são acrescidos cinco ensaios elaborados pelo crítico entre os anos de 1960 e 1970, que foram publicados em revistas acadêmicas. No "Suplemento" da nova edição, reúnemse: "A palavra de Deus"; "Alegoria e palavra em Iracema"; "Camões e Drummond: a máquina do mundo"; "A última voz de Krapp" e "A moratória em processo", de Silviano Santiago, e comentários de seus leitores contemporâneos, como "A urgência de "escrever contra", assinado por Eneida Cunha Leal; "Tempo de abutres e super astros", de Fred Coelho e "Sinal dos tempos: anacronismo e atualidade de Uma literatura nos trópicos", de André Botelho. 
de análise do crítico, que vão desde a Carta, de Pero Vaz de Caminha, e os sermões dos jesuítas, que marcam o período colonial, passando por alguns dos principais escritores da tradição literária brasileira (como José de Alencar, Machado de Assis, Raul Pompeia, José Américo de Almeida, Oswald de Andrade, Carlos Drummond de Andrade, entre outros) e chegando à produção cultural da década de 1970 (dialogando com a poesia e a música popular, e com nomes como Sérgio Sant'Anna, Caetano Veloso etc.).

Assim, por meio de diferentes autores, textos, tempos e espaços, Santiago (2000) oferece ao leitor seu mapa para percorrer uma literatura nos trópicos, afastando-se, logo de partida, de qualquer possibilidade de totalização sobre ela (o que poderia ser expresso se o título de seu livro fosse " $A$ literatura latino-americana"). Se existem "muitos mapas de um lugar e muitas histórias de um tempo" (FREDERIEKSE apud MCCLINTOCK, 2010, p.15), "O 'entre-lugar' do discurso latinoamericano", ensaio que abre Uma literatura nos trópicos e no qual concentraremos nossa atenção neste artigo, pode ser pensado como uma espécie de bússola a guiar o percurso crítico proposto pelo autor, sintetizando sua postura normativa quanto à tarefa do intelectual latinoamericano, bem como apresentando as principais linhas de força de sua construção teórico-metodológica para o estudo da cultura.

Escrito originalmente para uma conferência proferida em francês em 1971, “O ‘entre-lugar' do discurso latino-americano" apresenta como principal exercício analítico a sistematização e operacionalização do conceito de "entre-lugar". ${ }^{3}$ Em nossa hipótese, o "entre-lugar" carrega aquilo que qualificamos como ponto de vista pós-colonial, isto é, uma estratégia de leitura das matérias da cultura brasileira e latino-americana nova, cuja potencialidade está na emergência de um espaço conceitual entre a crítica e a Sociologia que elege a diferença como valor crítico e heurístico fundamental.

\footnotetext{
${ }^{3}$ A palestra foi ministrada pelo autor em março de 1971 na Universidade de Montreal, no Canadá, sob o título "L'entre-lieu du discours latino-américain". O texto foi publicado pela primeira vez dois anos depois, em 1973, numa edição da State University of New York at Buffalo, com o título "The Latin-American Literature: the Space In-between". Interessa sublinhar que se trata de um dos textos mais conhecidos de Santiago, com ampla circulação no contexto nacional e internacional, sendo os conceitos de "entrelugar" e o de "hibridez" amplamente mobilizados nas últimas décadas no campo dos estudos culturais e dos estudos pós-coloniais.
} 
Em que pese a variedade de perspectivas teórico-metodológicas que compõem os chamados "estudos pós-coloniais" (COSTA, 2006), sugerimos que Santiago compartilha com este campo o esforço de tecer críticas ao eurocentrismo teórico, questionando o universalismo etnocêntrico e as concepções hegemônicas de modernidade. Não se trata, aqui, de advogar pela filiação teórica do autor a um campo específico de conhecimento ou mesmo comparar sua proposta com a de outros autores que produziram categorizações e chaves de leituras que guardam semelhança com as de Santiago, como é o caso, por exemplo, de Gayatri Chakravorty Spivak (Pode o subalterno falar?, 1985), de Edward Said (Cultura e Imperialismo, 1993) ou de Homi K. Bhabha (O local da cultura, 1994).

Argumentamos, antes, que a operacionalização do conceito de “entre-lugar" abre possibilidades teóricas e apostas políticas que permitem analisar em nova chave os limites, os desafios e os alcances da concepção de modernidade inscrita na produção da cultura e nas experiências sociais a ela associadas. Afinal, esse ponto de vista, que qualificamos como póscolonial, está assentado no esforço de circunscrever a relação colonial como a mediação chave para a compreensão da cultura e da política na América Latina.

Tal sugestão, anote-se, guarda referência ao debate intelectual da época de escrita e publicação do ensaio, sendo possível observar que Santiago acompanha aspectos da discussão posta no pensamento social latino-americano na virada dos anos de 1960 para 1970, especialmente o debate sobre o subdesenvolvimento e a dependência (cf. CARDOSO; FALETTO, 1970). Por exemplo, o autor insiste, em sua primeira coletânea de ensaios, na recorrência do pacto colonial na vida política, econômica e cultural da América Latina. A crítica literária brasileira do período também se debruçou sobre questões semelhantes, como aparece em "Literatura e subdesenvolvimento" (1970), de Antonio Candido, e "As ideias fora do lugar" (1973), de Roberto Schwarz, ambos contemporâneos ao argumento de Silviano Santiago sobre o "entre-lugar".

Em lugares teóricos distintos, Candido e Schwarz de um lado, e Santiago de outro, chamam atenção para uma questão central na vida intelectual de países periféricos: como as ideias e os modelos europeus são assimilados (aclimatados, modificados, remodelados etc.) em novas geografias e circunstâncias históricas? De certo modo, esses intelectuais estavam preocupados em refletir sobre o significado de ter a diferença, a comparação e a distância como definidoras da produção das ideias e das 
matérias da cultura. ${ }^{4} \mathrm{Se}$, por um lado, esses críticos possuem distintos pontos de partida para ler a história da literatura brasileira - Candido e Schwarz concentram suas interpretações no momento de formação nacional, após a Independência política da metrópole portuguesa (1822), e Santiago, como já destacamos, elege textos escritos desde o século XVI como objeto de análise dos processos sociais e culturais brasileiros -, eles compartilham do esforço de refletir sobre as diferenças que se estabelecem entre os modelos importados e as formas brasileiras, procurando destacar a originalidade que pode se instaurar nos textos fabulados em um contexto historicamente dependente. ${ }^{5}$

O termo "dependente" - e lembremos que o subtítulo da primeira edição de Uma literatura nos trópicos é "ensaios sobre dependência cultural" -, sugere que, ainda que tenhamos resultados estéticos algumas vezes criativos e por vezes até ousados em termos de técnicas literárias, as condições do subdesenvolvimento têm sérios efeitos sociais e políticos, que precisam ser assimilados continuadamente pela crítica. Mesmo porque, se a questão da dependência - cultural, intelectual, política etc. - pode parecer datada, como lembra André Botelho (2019), os problemas que ela coloca permanecem em aberto, já que no cenário atual de globalização e da chamada "mundialização da cultura", ainda existe "uma geopolítica mundial da literatura e da cultura com relações e trocas assimétricas e recriações de hierarquias de vários tipos".

\footnotetext{
${ }^{4}$ Em "Nota prévia" à primeira edição de Uma literatura nos trópicos, Santiago aponta algo nessa direção: o intérprete sabe, diz ele, que seu trabalho "é o de saber colocar as ideias no devido lugar" (SANTIAGO, 2000, p.7). A fórmula "as ideias no lugar" não deixa de ser uma referência ao título irônico do ensaio de Schwarz que abre Ao vencedor as batatas (1977), cujo objetivo era perceber o modo como o Brasil historicamente "põe e repõe ideias europeias" (SCHWARZ, 2012, p. 28). Lembremos, ainda, que Candido, na década de 1940, já tinha sugerido que uma das tarefas dos intelectuais - sobretudo em contextos autoritários - é a de "esclarecer o pensamento e pôr ordem nas ideias" (CANDIDO, 1945, p. 37).

${ }^{5}$ Nessa linha, Alfredo Melo indica que, embora Candido, Schwarz e Santiago utilizem ferramentas teórico-metodológicas muito distintas - tomadas de empréstimo da antropologia social britânica, do marxismo e do pós-estruturalismo, respectivamente -, algo que os aproxima é "a teorização sobre uma derivação criativa na cultura brasileira", o que os permite complexificar as hierarquias e assimetrias de poder entre centro e periferia (MELO, 2013, p. 11, grifo nosso).
} 
Trata-se de uma geopolítica marcada pela heterogeneidade dos processos sociais e políticos que modulam, ao longo dos séculos, a modernidade. No caso específico da construção teórico-metodológica do "entre-lugar", as questões relativas às assimetrias e às hierarquizações acima aludidas são interpretadas a partir de um ponto em comum com os debates das Teorias da Dependência: a recorrência do pacto colonial. No argumento de Silviano Santiago (2000), se essa recorrência é o indício mais forte da repetição das posições duais centro e periferia, importa observar que a repetição é sempre produção da diferença.

\section{Da dependência à diferença: o "entre-lugar" como ponto de vista pós-colonial}

Cabe perguntar, então, o que se repete e como a diferença é produzida. Para avançar na compreensão dessa questão, interessa observar um deslocamento chave promovido por Santiago no conjunto de seus ensaios: menos do que destacar os impasses à formação da nação derivados do pacto colonial, como fazem alguns teóricos da dependência, o crítico toma o vínculo entre colônia e metrópole como uma relação colonial, num movimento analítico que permite qualificá-la como relação social e, portanto, aberta a múltiplas interações que promovem a comunicação entre tempos, espaços, culturas, visões de mundo e assim por diante.

Inscritas na dinâmica da sociedade, tais interações estão permanentemente atravessadas por conflitos, negociações e alianças variadas que, no entanto, produzem sempre como resultado a diferença. Assim, como relação social, a relação colonial opera de modo não dualista, sendo refeita não em função das posições binárias colônia e metrópole (ou periferia e centro), mas em razão da violência e da dominação social que marcam a relação entre esses dois espaços. Com esse modo de definir a relação colonial, torna-se possível observar com novas lentes tanto a diferença colonial, quanto a repetição estrutural de conflitos e impasses relativos a ela.

Afirmando que o empreendimento colonial contribuiu para o apagamento sistemático das diferenças e reconhecendo que a dependência cultural se tornou uma característica comum em países que sofreram brutais processos de colonização, Santiago (2000) propõe, então, uma reação agressiva, de desvio da norma das culturas do Terceiro Mundo em 
relação aos modelos colocados em circulação pelos centros econômicos e culturais hegemônicos. $\mathrm{O}$ crítico elege, para tanto, a diferença como valor crítico fundamental, isto é, faz uma aposta na relação de confronto entre tempos e geografias, na qual a periferia existe em relação ao centro, e não sob sua guarda. Dessa forma, teríamos que a relação colonial engaja e implica, também, as sociedades metropolitanas, inscrevendo-se em suas histórias e culturas. ${ }^{6}$

Aprofundando o argumento, sugerimos que as observações de Santiago (2000) reposicionam duas categorias fundamentais para pensar a relação colonial: as de tempo e de espaço, perturbando os postulados da continuidade e da linearidade, bem como a ideia de que o progresso é inevitável e de que há uma norma estética ou um modelo específico de desenvolvimento a ser venerado e perseguido. Seguindo essa linha, o "atraso" deixa de corresponder a uma questão temporal que encontraria seu equacionamento no curso das décadas ou de processos orientandos de modernização (cultural e econômica); antes, trata-se de um impasse social e político que engaja colônia e metrópole numa mesma relação social. Por essa razão, Santiago insiste que a alternativa aos colonizados é a de desvio da norma estabelecida pelos centros, e indica que a geografia latino-americana é um dos lugares sociais de "assimilação e agressividade, de aprendizagem e de reação, de falsa obediência" (SANTIAGO, 2000, p.15, grifos nossos). Abre-se, aqui, uma reflexão importante sobre a potência do "falar contra, escrever contra", de que tanto fala Santiago (2000, p.16) em seus ensaios. ${ }^{7}$

Em nossa leitura, essa potência do contra, espécie de reação cultural e de resistência intelectual à violência da colonização, realizase precisamente no "entre-lugar", uma vez que "falar em 'entre-lugar' implica considerar um lugar concreto e específico, e não um mero lugar de

\footnotetext{
${ }^{6}$ Note-se, ainda que de passagem, que essa é a dimensão crítica das lutas anti-coloniais pela descolonização da África e da Ásia entre as décadas de 1950 e 1960. Em termos de produção das ideias, aparece nos escritos de autores como Frantz Fanon, Jean Paul Sartre, Aimé Césaire etc.

${ }^{7}$ Potência que é aludida, de certo modo, em uma das epígrafes que abre o ensaio "O entre-lugar do discurso latino-americano", retirada do romance Quarup, onde lemos: “o jabuti que só possuía uma casca branca e mole deixou-se morder pela onça que o atacava. Morder tão fundo que a onça ficou pregada no jabuti e acabou por morrer. Do crânio da onça o jabuti fez seu escudo" (CALLADO, 1967 apud SANTIAGO, 2000, p. 8, grifos nossos).
} 
passagem, ou um 'não lugar' à lá Marc Augé” (BOTELHO, 2019, p. 365). Como espaço de enunciação, o "entre-lugar" do discurso latino-americano pode ser visto, ainda, como o lugar da produção do social, possibilitando que sociedades colonizadas reconheçam-se a partir de uma visada póscolonial, o que pavimenta caminhos importantes para a reviravolta nas noções de unidade, de pureza, de homogeneidade etc. (cf. SANTIAGO, 2000). Assim, esvaziam-se os nexos de sentido inerentes a tais noções, além de se desfazerem sinais de superioridade cultural que a metrópole pode guardar. O "entre-lugar" do discurso latino-americano converte-se, portanto, no espaço próprio do "renascimento colonialista", isto é, aquele que marca a apropriação do espaço sociocultural do Novo Mundo, bem como sua inscrição, pela conversão, no contexto da civilização ocidental.

Como consequência dos argumentos de Santiago, vale destacar que as manifestações artísticas e culturais brasileiras e latino-americanas não devem ser vistas ou avaliadas na chave da "influência" ou da "cópia" de modelos estrangeiros, o que as conferiria um estatuto secundário, reposto e atualizado em diferentes contextos e circunstâncias históricas. Observando a persistência de um estatuto secundário usualmente atribuído às culturas periféricas, e procurando desconstruir as ideias de "original" e de "cópia" que marcavam os estudos literários de seu tempo, em particular na área de Literatura Comparada, Santiago (2000) aventa um novo método crítico para interpretar as matérias culturais produzidas na América Latina.

Essa proposta parte de um conjunto de provocações feitas por Roland Barthes em $S / Z$, obra na qual o crítico francês tece uma leituraescritura de Sarrasine (1830), conto clássico de Honoré de Balzac. Dividindo os textos literários em textos legíveis e textos escrevíveis, Barthes (1970) sugere que os textos legíveis são aqueles tomados como clássicos, que podem ser lidos, mas não podem ser reescritos, pois seus sentidos são preexistentes e o leitor se submete a eles. Os textos escrevíveis, por outro lado, convidam o leitor a sair de uma posição de tranquilidade, já que eles não se realizam sem sua intervenção. Ou seja, os textos escrevíveis exigem uma postura ativa do leitor. Ao recuperar essa divisão entre textos legíveis e textos escrevíveis, Santiago (2000) argumenta que as leituras avidas realizadas por escritores de culturas periféricas não são inocentes e passivas, como muitos sugerem, e elas se justificam na busca por um texto escrevível, que possa lhes servir de modelo na organização de sua própria cultura. Nesse caso, a segunda obra 
(isto é, a obra produzida em contexto dependente) é fabulada a partir de um compromisso com o que já foi escrito, ou, para ser fiel aos termos de Santiago (2000, p. 20), por meio de uma "meditação silenciosa" sobre o modelo consagrado (em geral europeu). Mas essa meditação não é apenas silenciosa. Ela é também "traiçoeira" e, portanto, produz "algo novo": uma obra que pode "surpreender o modelo original em suas limitações", negando ou comportando uma "crítica da obra anterior" (SANTIAGO, 2000, p. 20). Por isso, para Santiago (2000, p. 19), é preciso examinar cuidadosamente o uso que o escritor latino-americano faz "de um texto ou de uma técnica literária que pertence ao domínio público".

Para desdobrarmos sua proposta crítica, vale acompanharmos de perto as observações do autor sobre o conto "Pierre Menard, autor del Quijote", escrito por Jorge Luis Borges e publicado em Ficciones (1944), que pode ser lido como uma metáfora da situação e do papel do escritor latino-americano, vivendo entre a assimilação do modelo estrangeiro e a necessidade de produzir uma "obra escrevível" que possa afrontar a primeira. No referido conto, o narrador apresenta a obra visível de Menard (escritos publicados durante a vida, admirados e catalogados inicialmente por uma mulher chamada Madame Bachelier) e acrescenta a ela uma obra invisível e "subterrânea, a interminavelmente heroica" (BORGES, 2007, p. 37). Trata-se do projeto de Menard de reescrever alguns capítulos de Dom Quixote, de Miguel de Cervantes. Madame Bachelier omitiu tal obra em sua catalogação, segundo nos conta o narrador, porque os capítulos que Menard escreve são idênticos ao modelo, "palavra por palavra e linha por linha". Entretanto, o que interessa ao narrador do conto, e não à toa Santiago (2000) recupera essas passagens, é apontar um paradoxo sobre as possibilidades da narração: os capítulos de Menard são mais sutis, embora também sejam verbalmente idênticos aos de Cervantes. Instaurando a prisão ao modelo, mas escrevendo séculos depois, Menard altera e torna "quase infinitamente mais rico", por deslocamento e anacronismo, os sentidos do primeiro texto (BORGES, 2007). A diferença entre as obras reside, então, no plano da leitura e da interpretação.

Esse paradoxo, contudo, não é o único elemento que chama atenção na leitura tecida por Santiago (2000) do conto de Borges. O crítico observa que o projeto de Menard de escrever o Dom Quixote é distinto de suas produções anteriores, como é o caso da transposição do poema "Cimetière Marin", de Paul Valéry. Na versão de Menard, Santiago (2000) recorda que os decassílabos do poema se transformam em alexandrinos, 
e ficamos diante de um suplemento sonoro que reorganiza a estrofe, alterando ainda o ritmo interno de cada verso. Aqui, a originalidade de Menard reside no movimento de "agressão ao original", uma pequena violência que assinala a ruptura entre o modelo e sua cópia (SANTIAGO, 2000). Seguindo a provocação de Santiago (2000), para Menard, como também para outros escritores latino-americanos, observamos certas recusas ao espontâneo, mas, ao mesmo tempo, escolhas conscientes diante de cada alteração. Ou seja, se a liberdade de criação é controlada pela primeira obra - bem como "a liberdade dos cidadãos dos países colonizados é vigiada de perto pelas forças da metrópole" -, a segunda obra se situa "na transgressão ao modelo, no movimento imperceptível e sutil de conversão, de perversão, de reviravolta" (SANTIAGO, 2000, p. 24, grifos nossos).

Enquanto Borges reivindicava um lugar na tradição cultural ocidental para o escritor e para a literatura argentina (quiçá latinoamericana) que colocava em xeque a ideia de escrita original e de plágio, Santiago (2000) argumenta enfaticamente que a tarefa da crítica é a de perceber o que o escritor cria de novo no seu movimento de agressão contra o modelo, pois na transformação do original à agressão do segundo texto, novas sutilezas - estéticas e históricas - são colocadas em circulação. Perquirir essas sutilezas, para o crítico, é uma das principais tarefas do intelectual latino-americano, que pode comparar com novas lentes as culturas periféricas e aquelas que consagram e rotinizam os modelos.

Antes de prosseguir, cabe um breve parêntese. Em "Eça, autor de Madame Bovary", terceiro ensaio de Uma literatura nos trópicos, essa estratégia de leitura de Santiago (ou seu método crítico, se quisermos) fica mais evidente. Nele, o autor chama atenção para a contingência da repetição e para os dilemas que envolvem as obras escritas nas culturas dependentes de outra cultura. Ao recorrer à metáfora de Pierre Menard, presente no título deste ensaio, mas invertendo seu sentido, Santiago (2000) aponta para uma familiaridade entre O Primo Basílio (1878) e o romance clássico de Gustave Flaubert, publicado poucas décadas antes, em 1856. Enquanto a obra de Cervantes é separada do texto de Menard por três séculos e por diferentes espaços geográficos, que são marcados pelo empreendimento colonial, os escritores analisados por Santiago (2000) são contemporâneos e pertencem ao espaço literário europeu, ainda que separados por distintas culturas (a francesa, de maior prestígio no século XIX, e a portuguesa e a brasileira, dependentes). 
Ao contrário do narrador do conto de Borges que procura destacar o lado invisível da obra de Menard, Santiago está preocupado em perceber as relações entre o lado visível das duas obras, que podem apontar certas transgressões que foram criadas a partir de um novo uso do modelo que foi tomado de empréstimo da cultura dominante. Seguindo essa leitura, ainda que a mudança do título seja sugestiva de que o autor português queria alterar o ponto de vista da narração, passando da esposa adúltera para o amante, a criação do personagem Ernestinho - autor também, que escreve uma peça durante o desenrolar da ação do romance e que reproduz o romance -, é o ponto chave da transgressão de Madame Bovary em $O$ primo Basílio (SANTIAGO, 2000).

Diante da variedade de entrechos apresentados no romance do português, e ao repensar categorias morais estabelecidas no texto primeiro, Santiago (2000) indica que esse romance torna mais rica e viva a obra de Flaubert. Não se trata, é importante pontuar, de uma interpretação que celebra acriticamente as obras forjadas em culturas dependentes. $\mathrm{O}$ interesse, antes, é o de chamar atenção para as diferenças - estéticas, sociais, políticas etc. - que se instauram nos textos de distintas culturas; diferenças essas que abrem novos caminhos teóricos para uma crítica política da cultura.

Fechando o parêntese e considerando as linhas gerais do método crítico proposto por Santiago (2000), sugerimos, então, que o "entrelugar" pode ser pensado como espaço conceitual e como lugar político que desestabiliza o saber etnocêntrico do mundo, isto é, um espaço no qual o imperialismo cultural pode ser desafiado. Aqui, podemos aventar a hipótese de que, para nosso crítico, as experiências de contextos periféricos (isto é, os lugares sociais da repetição diferenciada), são centrais para avançarmos em uma crítica ao eurocentrismo presente no pensamento ocidental hegemônico, que historicamente serviu (e continua servindo) de base para diferentes formas de colonialismo do poder e do saber.

Se Borges e outros escritores latino-americanos forjaram lugares de fronteira na cultura latino-americana que se afirmavam por proporcionar uma leitura irreverente da tradição ocidental - um exemplo são as orillas, uma das principais invenções estéticas do escritor portenho (cf., por ex., SARLO, 2008) -, o conceito de "entre-lugar" de Santiago, elegendo a diferença que se constrói nas trocas, indica a possibilidade de torção da norma estabelecida, de traição do modelo dominante, o que contribui com a desconstrução dos pontos de vista hegemônicos forjados, 
em geral, pelos países que agora são "ex-metrópoles”, mas ainda detêm um enorme poder político, econômico e cultural.

Radicalizando o argumento, na América Latina, como também em outras regiões periféricas do mundo como a África, a Ásia e a Oceania, que compartilham os efeitos do colonialismo e da periferização de sua produção cultural e intelectual, é possível tanto desestabilizar conceitos como os de "pureza", de "unidade", de "homogeneidade", como sugere Silviano Santiago, como apostar na criação de novos conceitos, como os de hibridismo, mestiçagem, heterogeneidade etc., que se tornam analiticamente mais relevantes para analisar os processos culturais e sociais às margens do sistema. Afinal, quando as noções de unidade e de pureza são perturbadas e quando a dualidade é negada, temos a emergência do híbrido e do mestiço, e abre-se um espaço crítico potente para ler a heterogeneidade dos processos históricos e políticos que constituem a modernidade. Mais do que isso, a descolonização dos pontos de vista dominantes é uma forma de pensar novas soluções para os dilemas sociais e políticos que enfrentamos. ${ }^{8}$

O “entre-lugar", então, pode ser compreendido como um espaço conceitual cujo valor teórico estaria associado à recusa de binarismos como "aqui" e "lá"; "antes" e "depois". Uma recusa importante, porque permite avançar na colocação de um problema que permanece

\footnotetext{
${ }^{8}$ Vale assinalar que, no campo dos estudos pós-coloniais, ao avançar na crítica às concepções hegemônicas e eurocêntricas da modernidade, tensionando certos conceitos chaves que pressupõem um sentido de "universalidade", pavimentam-se caminhos tanto para criação de novos vocábulos quanto para o alargamento das categorias modernas. No caso da criação de novos vocábulos, ao perturbar as noções de unidade e de pureza, como faz Silviano Santiago (2000), surgem conceitos como os de hibridez, mestiçagem, heterogeneidade, entre outros, que são bons exemplos da contribuição do pensamento social latino-americano para a teoria social mais ampla. Já no que se refere ao alargamento das categorias, conceitos como Estado, sociedade civil, esfera pública, democracia, cidadania, igualdade, racionalidade científica etc., ganham novas camadas de significado quando são confrontados com os sujeitos às margens do sistema e as diferentes experiências históricas da modernidade, como observa, entre outros, Dipesh Chakrabarty (2000). Não se trata, nos dois casos, de argumentar contra uma ideia de universal, mas de reconhecer que essa categoria precisa ser permanentemente contestada, porque o universal não é um espaço neutro (sem classe, gênero, sexualidade, raça, etnia, religião etc.), e que a conservação de certos conceitos com um sentido abstrato e determinado contribui para que se persista a herança de uma Europa colonialista sobre a qual se constrói a História.
} 
fundamental na sociedade contemporânea: quais são os desequilíbrios de poder que, afinal, habitam a diferença?

\section{A cultura e suas diferenças: uma conclusão}

Ao longo deste artigo, argumentamos em favor do "entre-lugar" como espaço definido de enunciação, bem como de construção do social e, em certa medida, de reconhecimento da sociedade sobre si. Do ponto de vista sociológico, sugerimos que a novidade teórico-metodológica aberta pelo conceito de "entre-lugar" permite observar a emergência daquilo que qualificamos como um ponto de vista pós-colonial.

Nossa sugestão persegue especialmente a desestabilização das categorias de tempo e de espaço operadas por Silviano Santiago, num movimento que permite complexificar o debate sobre a dependência cultural na medida em que observa a produção da diferença no interior da relação colonial. Ao olhar prioritariamente para essa relação, o autor nos convida a refletir sobre a heterogeneidade que marca o mundo social, recusando análises críticas - e posições políticas - assentadas no jogo de espelhos entre modelo e cópia. A recusa à noção de influência, como vimos, ancora-se no fato de que ela constrói uma temporalidade que "desinscreve" a história do processo de produção das ideias, esvaziando seus contextos e confinando suas possibilidades de circulação, deslocando as obras latino-americanas para fora do universo da imaginação e da invenção, restando-lhes apenas nutrirem-se "de uma outra [obra] sem nunca lhe acrescentar algo de próprio; uma obra cuja vida é limitada e precária, aprisionada que se encontra pelo brilho e pelo prestígio da fonte, do chefe de escola" (SANTIAGO, 2000, p. 17).

Como mencionamos nas páginas anteriores, ao quebrar a linearidade do tempo e perturbar a homogeneidade do espaço, Santiago (2000) desorganiza os eixos classificatórios comumente presentes em análises comparadas fundadas em conceitos de influência e de fonte - categorias de fundo lógico e linear -, e oferece um novo mapa para interpretar a literatura latino-americana. Para aprofundar a chave de leitura que propomos, seguimos a pista de Avtar Brah (2006) sobre o caráter contingente e contestado da produção de sentido de conceitos e categorias para pontuar que a emergência deste ponto de vista póscolonial é tributária de um modo específico de ler a cultura como campo de contestação no interior de práticas discursivas e materiais. 
Se acompanharmos, por exemplo, a marcha dos argumentos desenvolvidos por Santiago em outros momentos de sua obra - como no ensaio "Apesar de dependente, universal" (reunido em Vale quanto pesa, 1982), cuja tese é complementar à tecida em "O entre-lugar do discurso latino-americano" -, observamos que o crítico arrisca a hipótese de que a dependência, que é inescapável, instaura uma diferença (estética e histórica) incontornável, e as produções culturais de um país historicamente subordinado no concerto geral das nações podem ser as respostas não etnocêntricas que as culturas dependentes dão aos valores culturais e até mesmo morais estabelecidos pelas metrópoles, quadro no interior do qual, aliás, o conceito de universalidade passa a existir. Nesse ponto, vale observar mais de perto o desenvolvimento do argumento do autor. Para ele, o texto descolonizado pode ser mais rico e sutil, porque há nele

(...) uma representação do texto dominante e uma resposta a esta representação no próprio nivel da fabulação, resposta esta que passa a ser um padrão de aferição cultural da universalidade tão eficaz quanto os já conhecidos e catalogados. [...] A universalidade ou bem é um jogo colonizador, em que se consegue pouco a pouco a uniformização ocidental do mundo, a sua totalização, através da imposição da história europeia como História universal, ou bem é um jogo diferencial em que as culturas, mesmo as em situação econômica inferior, se exercitam dentro de um espaço maior, para que se acentuem os choques das ações de dominação e das reações de dominados. A verdade da universalidade colonizadora e etnocêntrica está na metrópole, não há dúvida; a verdade da universalidade diferencial, como estamos vendo com a ajuda da Antropologia, está nas culturas periféricas (SANTIAGO, 1982, p. 23-24, grifos nossos).

Em “Apesar de dependente, universal”, vemos que três noções são caras ao argumento de Santiago: a de "antropofagia cultural", de Oswald de Andrade; a de "traição da memória", de que fala Mário de Andrade; e a de "corte radical", proposto por grupos de vanguarda e, em particular, pelo grupo paulista dos concretistas. Trata-se de noções que, reconhecendo a dependência cultural das culturas periféricas, que é uma das heranças mais marcantes do empreendimento colonial, buscam a subversão e especulam as possibilidades de contestar modelos hegemônicos. 
A emergência de um ponto de vista pós-colonial no conjunto dos ensaios de Silviano Santiago corresponde, então, a um esforço de colocar em relação micro e macros regimes de poder, o que, por sua vez, confere densidade teórico-metodológica e normativa à diferença como valor crítico e heurístico.

Desse modo, é em decorrência do caráter relacional da diferença, constituído e organizado em relações sistemáticas por meio de discursos econômicos, culturais, políticos e de práticas institucionais, que se pode compreender a relação colonial como mediação chave para desvendar aspectos da vida cultural e política latino-americana. Recuperando os termos próprios de Santiago, "entre o sacrifício e o jogo, entre a prisão e a transgressão, entre a submissão ao código e a agressão, entre a obediência e a rebelião, entre a assimilação e a expressão" o "entre-lugar" ganha corpo e, mesmo clandestinamente, pode realizar o "ritual antropófago da literatura latino-americana" (SANTIAGO, 2000, p. 25).

Um ritual que, no entanto, não corresponde à integração harmônica entre raças ou culturas da América Latina, tampouco implica na afirmação de uma miscigenação que, no limite, pode refazer a unidade na diferença. Ao contrário, a proposta de ler a cultura a partir de um ponto de vista póscolonial é precisamente a de desvelar o caráter etnocêntrico de boa parte das fabulações teóricas elaboradas sobre nós. Tal proposta, uma espécie de novidade teórico-metodológica na década de 1970, continua oferecendo pistas de leitura importantes para as ciências sociais contemporâneas, que nas últimas décadas têm perseguido o esforço de descolonizar a teoria ocidental hegemônica como uma das vias de descolonização do poder.

Como vimos no argumento de Santiago, as análises críticas amparadas por noções de fonte e de influência apenas seriam capazes de produzir mapeamentos e classificações intelectuais relativamente estáveis e cristalizadas nos binarismos "colonizador/colonizado"; "metrópole/ colônia"; "centro/periferia"; "Europa/Novo Mundo" etc. Ler os processos sociais e a cultura a partir e por meio de tais binarismos implica na adesão ao colonialismo e ao seu desdobramento neocolonial responsável pelo estabelecimento gradual "num outro país de valores rejeitados pela metrópole" (SANTIAGO, 2000, p. 19), criando um movimento de mão única no interior do qual os objetos culturais do polo colonizado seriam "mera cópia - silêncio -, uma cópia muitas vezes fora de moda" (SANTIAGO, 2000, p. 15). 
Assim, tanto a visão sobre o exótico - comum nas interpretações locais e especialmente nas estrangeiras sobre a América Latina -, quanto a visão sobre a cópia "fora de moda" alimentam o etnocentrismo teórico, não apresentando "em sua essência diferença alguma do discurso neocolonialista", já que ambos "falam de economias deficitárias" (SANTIAGO, 2000, p. 20). Afastando-se de qualquer retórica do déficit, Santiago (2000, p. 14) argumenta que a "mistura sutil e complexa entre o elemento europeu e o elemento autóctone" ao dar origem ao híbrido, que marca a sociabilidade nos trópicos, também é atravessada pela violência colonial, já que foram impostos aqui, de modo brutal, um código linguístico e um código religioso europeu que apagou a língua e o sistema sagrado dos indígenas.

É por meio do recurso aos escritos do período colonial que Santiago consegue demonstrar que os portugueses afirmavam que os índios brasileiros estariam inclinados à conversão religiosa, porque imitavam "naturalmente" os gestos dos cristãos durante a missa. Uma das principais violências da relação colonial, para o autor, é instituir o nome de Deus, o que equivale a "impor o código linguístico no qual seu nome circula em evidente transparência" (SANTIAGO, 2000, p. 12). ${ }^{9} \mathrm{O}$ código religioso e o linguístico foram, portanto, duas linhas de força propulsoras da colonização portuguesa e estavam intimamente ligados, propagando a cultura ocidental entre nós. Assim, a partir do "extermínio constante dos traços originais, pelo esquecimento da origem" (SANTIAGO, 2000, p. 14), a América foi transformada em cópia. Mas sua originalidade, como insiste Santiago (2000, p. 14), não se encontra na cópia do modelo original, e sim na sua origem, apagada de modo brutal pelos colonizadores, fazendo com que "o fenômeno de duplicação se estabelecesse como a única regra válida de civilização".

Por razões como essas, Santiago (2000) insiste que é preciso refletir sobre o lugar do discurso literário latino-americano no confronto com o europeu, elegendo a diferença como valor crítico fundamental, porque ela possibilita um novo olhar para o processo social e para a produção das ideias, indo na contramão da "máquina do colonialismo" (SANTIAGO, 1982), para a qual há uma única forma de refletir e experimentar o mundo. Em outros termos, ao questionar se um país que

\footnotetext{
${ }^{9}$ Esse argumento é desenvolvido de modo mais detido no ensaio "A palavra de Deus" (cf. SANTIAGO, 2019).
} 
é historicamente marcado por desequilíbrios econômicos pode possuir independência cultural, o crítico propõe como desafio teórico e político pensar a diferença que se instaura nos textos de culturas distintas, uma diferença que deve ser analisada não apenas em termos estéticos, como também históricos, sociais, políticos e culturais. A partir dessa empreitada, torna-se possível imaginar novas formas de pensar e agir na sociedade contemporânea.

Em nosso argumento, essa estratégia de ler a literatura brasileira e latino-americana a partir de um ponto de vista pós-colonial ganha densidade analítica ao longo da produção ensaística do crítico, em particular com a fabulação de conceitos como "cosmopolitismo do pobre" e "inserção", ${ }^{10}$ conceitos que guardam alguma afinidade eletiva com o de "entre-lugar", uma vez que, cada qual a seu modo, tais conceitos correspondem a respostas normativas ao eurocentrismo predominante nas ciências humanas de modo geral e nos estudos literários em particular. ${ }^{11}$ Em poucas palavras, indicamos que o "entre-lugar" como espaço crítico aposta na desconstrução e no deslocamento político do essencialismo, na medida em que inscreve a diferença e a repetição no processo social, repondo o movimento e a circulação - não horizontal, constrangida pela dominação neocolonial, mas aberta às contingências históricas ajudando a ajustar o olhar do crítico para um ponto central: a circulação e o movimento de obras, ideias e pessoas.

Enfatizando um discurso crítico que assinale os elementos das obras que marcam a diferença, e não os saberes fundados apenas nas semelhanças e/ou continuidades, Silviano Santiago coloca questões instigantes para variadas agendas de pesquisa em movimento na área de Pensamento Social Brasileiro. Um dos desafios analíticos e metodológicos que ainda temos nessa área é o de ajustar as lentes com as quais comparamos (autores, textos e contextos). Talvez seja o caso - e o momento histórico - de olhar com mais atenção para a circulação e o movimento de obras, ideias e

\footnotetext{
${ }^{10}$ O conceito de "inserção" é uma contraposição ao chamado "paradigma da formação" e, mais precisamente, à leitura da história literária brasileira tecida por Antonio Candido e pelo grupo de seus assistentes.

${ }^{11}$ Vale apontar outros ensaios do crítico que colocam essas questões, como é o caso de: "Atração no Mundo", reunido em Cosmopolitismo do pobre (2004), "Inserção da América Latina" (O Estado de S. Paulo, 2011) e "A anatomia da formação. A literatura brasileira à luz do pós-colonialismo" (Folha de S. Paulo, 2014).
} 
pessoas e, como Santiago, eleger a diferença como parâmetro analítico fundamental de nossas interpretações, uma diferença que, potencialmente, jogue luz aos velhos e aos novos efeitos do colonialismo nas sociedades periféricas. Em outros termos, retomando as indagações e provocações feitas por Santiago há mais de quarenta anos, talvez tenhamos algumas pistas preciosas para desvendar os lastros da "máquina do colonialismo" que estão sendo atualizados na contemporaneidade. ${ }^{12}$

\section{Referências}

BARTHES, Roland. S/Z. Paris: Seuil, 1970.

BORGES, Jorge Luis. Pierre Menard, autor de Quixote. In: Ficções. Tradução de Davi Arrigucci Jr. São Paulo: Companhia das Letras, 2007. p. 34-45.

BOTELHO, André. Sinal dos tempos: anacronismo e atualidade de Uma literatura nos trópicos. In: SANTIAGO, Silviano. Uma literatura nos trópicos. Recife: CEPE, 2019. p. 361-379.

BRAH, Avtar. Diferença, diversidade, diferenciação. Cadernos Pagu, Campinas, v. 26, p. 329-376, 2006. DOI: https://doi.org/10.1590/S010483332006000100014.

CANDIDO, Antonio. Depoimento. In: NEME, Mário (coord.). Plataforma da Nova Geração. Porto Alegre: Globo, 1945. p. 31-40.

CARDOSO, Fernando Henrique; FALETTO, Enzo. Dependência e desenvolvimento na América Latina: ensaio de interpretação sociológica. Rio de Janeiro: Zahar, 1970.

\footnotetext{
${ }^{12}$ Além dessa possível contribuição teórica para uma área de conhecimento mais específica, gostaríamos de deixar indicado que avançar nas reflexões provocadas pelo crítico em seus ensaios, especialmente a partir e por meio do conceito de "entre-lugar", é uma das tarefas intelectuais mais urgentes no tempo presente. Isso porque, na atual conjuntura, líderes de extrema-direita no Brasil e em outras partes do mundo vêm disputando a definição de suas nações a partir de ideias de "pureza" e de "unidade", negando o hibridismo, a heterogeneidade, a diversidade e a diferença (cultural, religiosa, racial, sexual etc.) que foram centrais nas discussões teóricas e políticas das últimas décadas. Como vimos ao longo deste artigo, é preciso "falar contra, escrever contra" a "álgebra do conquistador", segundo a qual a "unidade é a única medida que conta" (SANTIAGO, 2000, p. 13, grifo nosso).
} 
CHAKRABARTY, Dipesh. Provincializing Europe: Postcolonial Thought and Historical Difference. New Jersey: Princeton University Press, 2000.

COSTA, Sérgio. Desprovincializando a Sociologia: a contribuição póscolonial. Revista Brasileira de Ciências Sociais, São Paulo, v. 21, n. 60, p. 117-134, 2006. DOI: https://doi.org/10.1590/S0102-69092006000100007

CUNHA, Eneida Leal. A urgência de "escrever contra". In: SANTIAGO, Silviano. Uma literatura nos trópicos. Recife: CEPE, 2019. p. 342-349.

MCCLINTOCK, Anne. Couro imperial: raça, gênero e sexualidade no embate colonial. Tradução de Plínio Dentzien. Campinas: Editora da Unicamp, 2010.

MELO, Alfredo Cesar. Por um comparativismo do pobre: notas para um programa de estudos. Revista Brasileira de Literatura Comparada, Rio de Janeiro, v. 15, n. 23, p. 9-30, 2013.

SANTIAGO, Silviano. Apesar de dependente, universal. In: . Vale quanto pesa: ensaios sobre questões político-culturais. Rio de Janeiro: Paz e Terra, 1982. p. 13-24.

SANTIAGO, Silviano. Glossário de Derrida. Rio de Janeiro: Francisco Alves, 1976.

SANTIAGO, Silviano. Uma literatura nos trópicos. Recife: CEPE, 2019. SANTIAGO, Silviano. Uma literatura nos trópicos: ensaios sobre dependência cultural. 2. ed. Rio de Janeiro: Rocco, 2000.

SARLO, Beatriz. Jorge Luis Borges, um escritor na periferia. Tradução de Samuel Titan Jr. São Paulo: Iluminuras, 2008.

SCHWARZ, Roberto. Ao vencedor as batatas: forma literária e processo social nos inícios do romance brasileiro. São Paulo: Duas Cidades: 34, 2012. p. 11-31. 